\title{
ВОПРОСЫ ПРАВОВОГО РЕГУЛИРОВАНИЯ В СИСТЕМЕ УПРАВЛЕНИЯ ОТХОДАМИ
}

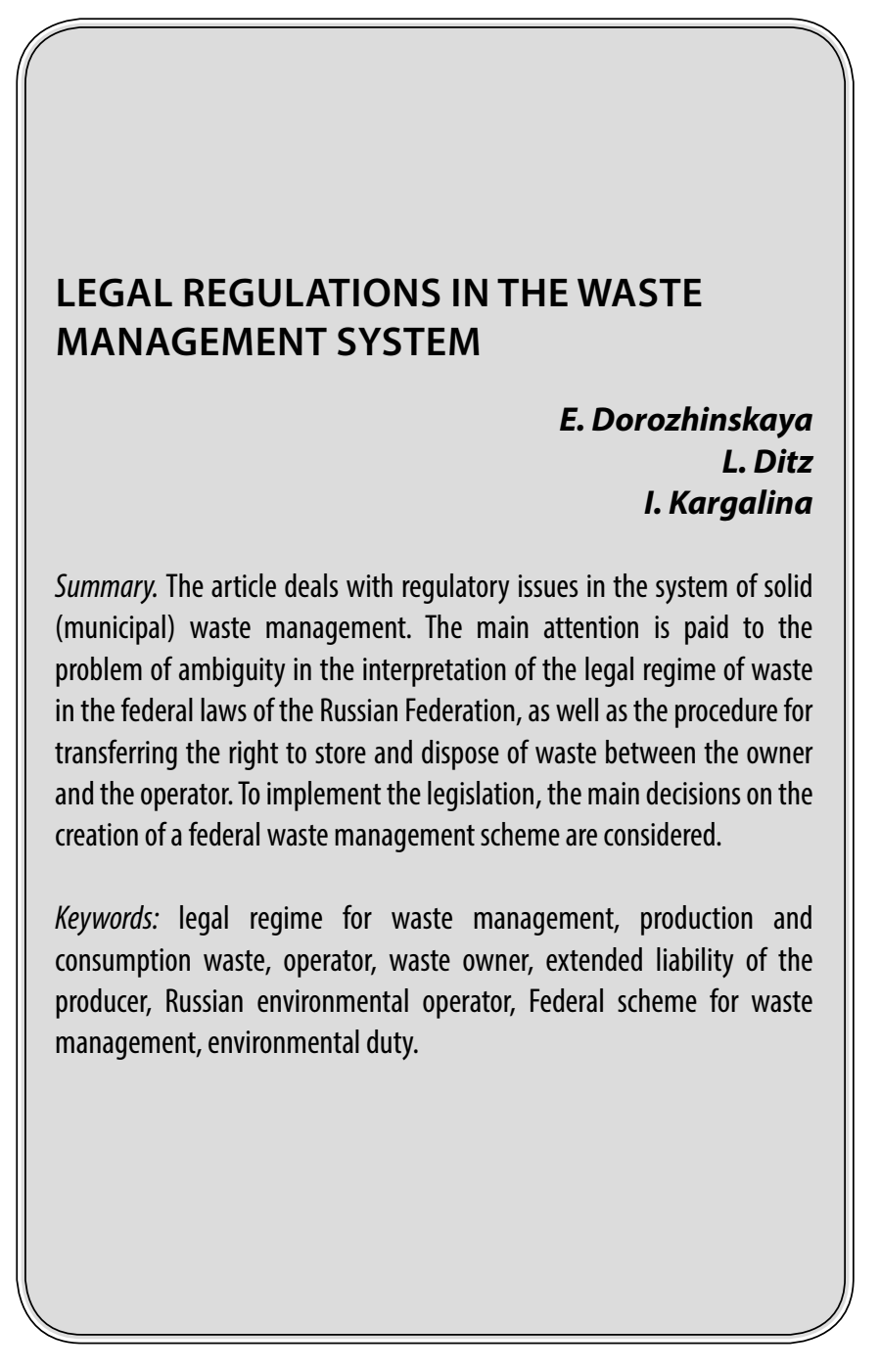

$\mathbf{H}$ а территории Российской Федерации уделяется большое внимание вопросам обращения и управления отходами производства и потребления. Накопление твердых (бытовых) коммунальных отходов стало наиболее острой не только экологической, но и экономической проблемой, что требует серьезного реформирования системы государственного регулирования в области управления.

Обращение с отходами - сложная территориальная, государственная и общемировая экологическая проблема. Поэтому вопросы утилизации отходов с каждым годом поднимаются все выше в повестке экологических проблем. Причиной, вероятно, является то, что, несмотря на множество регламентирующих этот процесс нор-
Дорожинская Елена Анатольевна К.ю.н., доцент, Сибирский институт управления филиал Российской академии народного хозяйства и государственной службы при Президенте РФ,

2. Новосибирск

sofia_1974@mail.ru

Дити Людмила Юрьевна

К.б.н., доцент, Новосибирский государственный университет экономики и управления, г. Новосибирск

I.ditz@mail.ru

Каргалина Ирина Анатольевна

Старший преподаватель, Сибирский институт управления - филиал Российской академии народного хозяйства и государственной службы при Президенте $P Ф$, г. Новосибирск kiabiavir@inbox.ru

Аннотация. В статье рассмотрены вопросы нормативно-правового регулирования в системе обращения с твердыми (коммунальными) отходами. 0сновное внимание уделено проблеме неоднозначности трактовки правового режима отходов в федеральных законах РФ, а также процедура перехода права на хранение и утилизацию отходов между собственником и оператором. Для реализации норм законодательства рассмотрены основные решения по созданию федеральная схема обращения с отходами.

Ключевые слова: правовой режим обращения с отходами, отходы производства и потребления, оператор, собственник отходов, расширенная ответственность производителя, Российский экологический оператор, Федеральная схема обращения с отходами, экологический сбор.

мативно-правовых актов, эффективность утилизации оставляет желать лучшего.

На данный момент в мировой практике наиболее распространена утилизация отходов тремя методами:

- переработка мусора с использованием раздельного сбора отходов.

- сжигание отходов на мусоросжигательных заводах.

- вывоз мусора на мусорные полигоны.

Применение данных подходов позволяет снизить негативное влияние накопленных и накапливаемых отходов на природную среду, а также решить экономическую проблему использования вторичных источников сырья. 
Основными направлениями для снижения негативного воздействия отходов являются:

- нормативно-правовое регулирование в области обращения с отходами производства и потребления;

- внедрение механизмов экономического регулирования и инвестиционного стимулирования деятельности по сбору, накоплению, утилизации, обезвреживанию, захоронению и переработки отходов.

Вопросам совершенствования законодательных положений правовых законов в системе обращения с отходами уделяется большое значение.

Стоит обратить внимание на гражданско-правовой аспект определения правового режима отходов, поскольку практика демонстрирует неоднозначность правового регулирования в этом вопросе.

Начнем с прямого указания статьи 4 федерального закона от 24.06.1998 № 89-Ф3 «Об отходах производства и потребления» (далее - федеральный закон № 89-Ф3) на то, что «право собственности на отходы определяется в соответствии с гражданским законодательством» [3]. Но в гражданском законодательстве отсутствуют нормы, регулирующие как правовой режим отходов в целом, так и движение прав на них, а также регулирование их включения в гражданский оборот. А ведь эти манипуляции должны быть неизбежны, исходя из толкования понятия «утилизация отходов», закрепленного статьей 1 федерального закона № 89-Ф3.

Если начать с определения места отходов в системе объектов гражданских прав, безусловно, нельзя обойтись без упоминания статьи 128 ГК РФ [1]. Отходы относятся к вещам, которые образовались в процессе производства, или в процессе потребления. Но вещи в традиционном цивилистическом понимании создаются в процессе производства именно для того, чтобы обрести именно такую конечную форму. Отходы же являются побочным эффектом какого-либо процесса (либо производства, либо потребления), не являясь его итоговой целью.

При попытке классификации отходов как гражданско-правовой объекта можно утверждать, что отходы, как правило, являются вещами движимыми, простыми, определенными родовыми признаками и, безусловно, потребляемыми.

Но с точки зрения оборотоспособности множество правовых положений не определены, ведь то, что отходы являются объектами гражданских прав, не делает их автоматически объектами гражданского оборота.
С одной стороны, п. 2 ст. 129 ГК РФ гласит о возможности введения ограничений оборотоспособности объектов гражданских прав либо по субъектному составу участников оборота, либо по видам возможных сделок, совершаемых по специальному разрешению [1].

Примером может послужить действующий по сегодняшний день указ Президента РФ от 22.02.1992 № 179 «О видах продукции (работ, услуг) и отходов производства, свободная реализация которых запрещена» [7], Этот Указ запрещает свободную реализацию отходов производства радиоактивных материалов и взрывчатых веществ. Также свободной реализации не подлежат отходы, которые образовались в результате уничтожения химического оружия [11]. Логика законодателя в этом вопросе совершенно ясна: подобные отходы создают угрозу либо экологической, либо экономической безопасности общества и государства. Но к твердым бытовым отходам эти нормы в целом не применяются.

С другой стороны, согласно п. 3 статьи 4 федерального закона № 89-Ф3 устанавливалось право собственника отходов I - IV класса опасности отчуждать их лишь в том случае, если у приобретателя «имеется лицензия на осуществление деятельности по использованию, обезвреживанию, транспортированию, размещению отходов не меньшего класса опасности». В настоящее время это положение утратила силу, соответственно, ограничение для утилизации многих видов отходов перестало быть актуальным, границы оборотоспособности расширились.

Иные нормы главы 14 ГК РФ тоже применимы к обороту отходов лишь частично. Например, М. В. Пономарев отмечал, что в ходе анализа содержания ч. 1 ст. 220 ГК РФ можно сделать следующий вывод: при переработке отходов в новую движимую вещь, при условии, что право собственности на отходы не перешло по договору от их собственника к переработавшему их лицу, то право собственности на полученную из них продукцию должно принадлежать собственнику отходов [4]. С этим можно согласиться при условии, что точно известно, кто именно является собственником отходов.

Описанные процессы полностью соотносятся с принципами государственной политики в области обращения с отходами, которые позволяют использовать современные технологии комплексной переработки материальных ресурсов для уменьшения количества отходов.

Но, возвращаясь к вопросу о праве переработки с гражданско-правовой точки зрения, необходимо уточнить статус собственника отходов. 
Для начала стоит развести понятия «собственник отходов» и «оператор». Под «оператором» законодатель определил множество субъектов, фигурирующих в данной области. К ним относятся российский экологический оператор (публично-правовая компания) [8], федеральный оператор [6], региональные операторы, а также индивидуальные предприниматели, которые осуществляют свою деятельность по обращению с отходами.

С гражданско-правовой точки зрения понятие «собственник» звучит вполне традиционно. Но когда речь идет о «собственнике отходов, возникает вопрос: с какого момента он становится таковым? Приобретая вещь, лицо традиционно желает извлечь из неё максимум полезных свойств, после чего неизбежно остаются отходы как результат использования вещи. Лицо автоматически продолжает оставаться собственником этих «остатков» вещи и может определить для них юридическую судьбу. Например, он может отказаться от права собственности на эти отходы, согласно статьи 236 ГК РФ, заключив договор купли-продажи или иными законными путями [1].

Описанный сценарий аналогичен и для собственников-физических лиц, и для собственников-субъектов предпринимательской деятельности. Но правовое регулирование действий этих субъектов отличается. Например, при анализе понятия «твердые коммунальные отходы» становится заметно, что законодатель таковыми считает преимущественно результаты потребления/ использования вещей физическими лицами в целях удовлетворения личных и бытовых нужд, что не характерно для субъектов предпринимательской деятельности.

После того, как собственник своей волей избавляется от отходов, можно было бы предполагать, что его право собственности на эти «остатки вещи» прекращается, если бы не нормы статьи 236 ГК РФ [1], гласящие, что отказ от права собственности не влечет прекращения прав до приобретения права собственности на неё другим лицом, момент которого законодателем четко не определен.

Действительно, федеральный закон № 89-Ф3 [1] регулирует множество процессов, осуществляемых с уже выброшенными собственником отходами: накопление отходов, их хранение, транспортирование, размещение, захоронение, непосредственно утилизация и т.д. Все эти процедуры как минимум подразумевают принятие операторами упомянутых отходов в собственное владение, а как максимум - обращение их в собственность. Но закон не всегда дает возможность однозначно определить момент прекращения права собственности бывшего собственника вещи (отходов).
Гражданское законодательство устанавливает, что право собственности на вещи (отходы) возникает у приобретателя, к которому относится оператор, с момента купли-продажи или иного договора о передачи в собственность.

Важность определения момента перехода права собственности на отходы и определения их надлежащего собственника состоит в том, что на собственников отходов должны возлагаться обязательства по их содержанию до приобретения право другим предпринимателем [2].

В результате анализа сложившейся правовой реальности без ответа остаются два вопроса.

Первый вопрос, из каких норм законодательства следует, что оператор (или иной субъект отношений по переработке и утилизации отходов) становится собственником отходов? Действующие нормы как гражданского, так и иного отраслевого законодательства не позволяют определить ответ.

Второй вопрос, также оставшийся без ответа: на основании какого именно договора оператор (или иной субъект) становится собственников отходов, чтобы потом получить право осуществлять их утилизацию во всех предусмотренных законом формах и получать от этого экономический результат?

В настоящее время в договоре с региональным оператором на оказание услуг по обращению с твердыми коммунальными отходами нет ни слова о переходе права собственности. Поэтому, право собственности на отходы и условия его приобретения имеют большое значение при рассмотрении вопрос компенсации причиненного ущерба окружающей среде [10].

Вопросы утилизации отходов с каждым годом поднимаются все выше в повестке экологических проблем. Причиной, вероятно, является то, что, несмотря на множество регламентирующих этот процесс нормативно-правовых актов, эффективность утилизации оставляет желать лучшего.

Огромное количество отходов обусловлено высокой ресурсоемкостью отечественной промышленности и большим процентом вещества, уходящим в отходы технологической цепочки. Использование же отходов в дальнейшем производстве осложняется необходимостью лицензирования данного вида деятельности, сложностью перевода отходов в ресурс.

Вместе с тем использование (утилизация) и обезвреживание отходов являются технологически сложными и экономически затратными. Захоронение отходов 
на полигонах не требует сложных технологий и больших капиталовложений. Именно этот самый дешевый способ удаления отходов и доминирует в России.

Чтобы обеспечивать соблюдение законодательства России в области обращения с ТБО, стимулировать инвестиционную активность в этой области и способствовать реализации национального проекта «Экология» согласно указа президента Владимира Путина от 14 января 2019 года была создана Публично-правовая компания «Российский экологический оператор» [8].

Главная цель «Российский экологический оператор»обеспечить реализацию норм законодательства в области обращения с твердыми коммунальными отходами (ТKO) и создать систему вторичной переработки сырья. «Российским экологическим оператором» создается в настоящее время «Федеральная схема обращения с TKO».

Для стимулирования деятельности по обращению с отходами и их использованию для получения вторичного сырья в 2017 году был введен новый механизм экономического регулирования, согласно которого устанавливается расширенная ответственность производителей (РОП) за утилизацию выпущенной продукции в конце ее жизненного цикла.

Основной целью введения РОП является необходимость утилизации и размещением отходов. Это приводит к необходимости развития перерабатывающей отрасли,

Согласно ст. 24.2 Федерального закона от 24.06.1998 № 89-Ф3 «О6 отходах производства и потребления» (в ред. от 28.12.2016) установлены три варианта исполнения РОП [3]:

- выполнение производителями товаров нормативов утилизации;
- обязательное заключение договоров с предприятиями по переработки отходов;

- необходимость уплаты экологического сбора.

Принцип экономического стимулирования утилизации отходов ставит производителя перед выбором либо заключать договоры на утилизацию с переработчиками отходов, либо платить экологический сбор, что не всегда экономически выгодно.

Пока в России система экологического сбора неэффективна. Причиной является то, что у Росприроднадзора, как у администратора экологического сбора, отсутствуют данные о фактическом количестве компаний, которые должны выполнять правила РОП. Из-за этого сложно выявить тех производителей и импортеров, которые эти правила не соблюдают.

Неэффективность расходования средств от экологического сбора, который является основным природоохранным платежом, приводит к тому, что цели РОП не достигаются, механизм не работает.

Федеральным законом от 26 июля 2019 года № 225Ф3 [9] внесены изменения в Федеральный закон «Об отходах производства и потребления», согласно которым в рамках реализации проекта «Комплексная система обращения с твёрдыми коммунальными отходами» национального проекта «Экология» предусмотрена разработка федеральной схемы обращения с твёрдыми коммунальными отходами [5].

Таким образом, совершенствование нормативно-правового и экономического регулирования в области обращения с отходами производства и потребления позволит повысить инвестиционную активность в этой области и способствовать реализации национального проекта «Экология».

\section{ЛИТЕРАТУРА}

1. Гражданский кодекс Российской Федерации / [Электронный ресурс] — Режим доступа.— URL: https://grazhdanskiy-kodeks.ru/

2. Гордиенко И. И. Правовое регулирование утилизации объектов недвижимости, находящихся в государственной собственности // Актуальные проблемы российского права. — 2019. — № 9. - С. 185-192.

3. Об отходах производства и потребления: федеральный закон от 24.06.1998 № 89 -Ф3 (ред. от 27.12.2019) // Собр. законодательства РФ.— 1998.— № 26. - С. 3009.

4. Пономарев М.В.Право собственности на отходы: правовые проблемы реализации и перехода // Журнал российского права.— 2017.— № 8.C. 53-64.

5. Постановление Правительства Российской Федерации от 25.12.2019 № 1814 «0 разработке, утверждении и корректировке федеральной схемы обращения с твердыми коммунальными отходами» http://base.garant.ru/.

6. Распоряжение Правительства РФ от 14.11.2019 № 2684-р «06 определении федерального оператора по обращению с отходами I и II классов опасности» // Собр. законодательства РФ. — 2019. — № 46. — Ст. 6556.

7. Указ Президента РФ от 22.02.1992 № 179 (ред. от 30.12.2000) «0 видах продукции (работ, услуг) и отходов производства, свободная реализация которых запрещена» // Рос. Газ. - 1992. - 16 марта. 
8. Указ Президента РФ от 14.01.2019 № 8 «0 создании публично-правовой компании по формированию комплексной системы обращения с твердыми коммунальными отходами «Российский экологический оператор» //Собр. законодательства РФ. — 2019. — № 3.— Ст. 234.

9. Федеральный закон от 26.07.2019 N225-Ф3 «0 внесении изменений в Федеральный закон «0б отходах производства и потребления» / [Электронный ресурс] — Режим доступа.—URL: http://www.consultant.ru/document/.

10. Федеральный закон от 10.01.2002 N7-Ф3 (ред. от 27.12.2019) «06 охране окружающей среды» / [Электронный ресурс] — Режим доступа.— URL: https:// www.zakonrf.info/zakon-ob-ohrane-okr-sredy/.

11. Федеральный закон от 02.05.1997 № 76-Ф3 (ред. от 05.02.2018) «0б уничтожении химического оружия» // Рос. Газ. — 1997.

\section{๑ Дорожинская Елена Анатольевна ( sofia_1974@mail.ru ),}

Дитц Людмила Юрьевна ( I.ditz@mail.ru ), Каргалина Ирина Анатольевна ( kiabiavi@@inbox.ru).

Журнал «Современная наука: актуальные проблемы теории и практики»

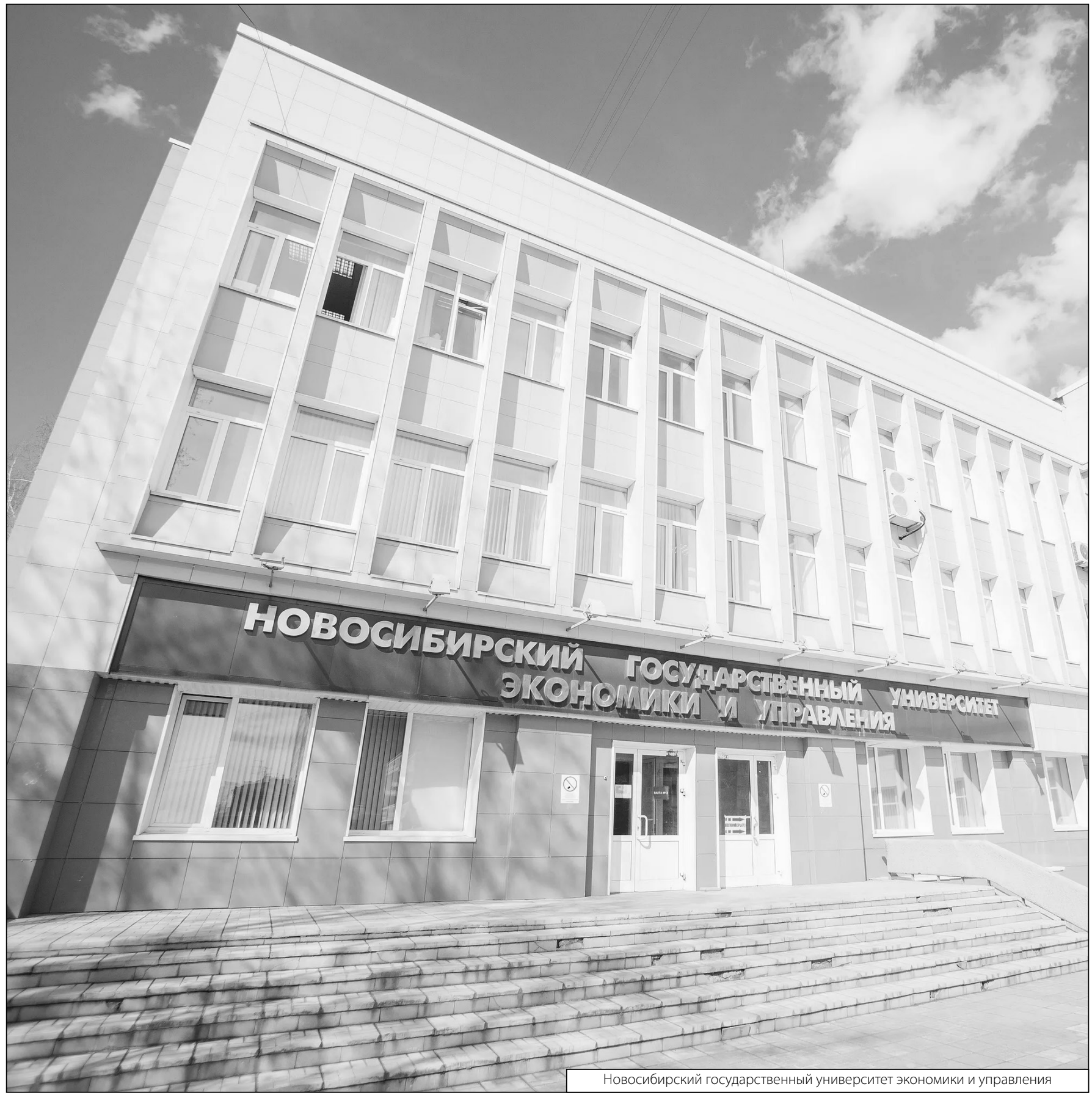

